Association for Information Systems AIS Electronic Library (AISeL)

ICIS 1989 Proceedings

International Conference on Information Systems

1989

\title{
GROUP DECISION SUPPORT SYSTEMS: THE CULTURAL FACTOR
}

T. H. Hao

National University of Singapore

K.S. Raman

National University of Singapore

Richard T. Watson

University of Georgia

Follow this and additional works at: http://aisel.aisnet.org/icis1989

\section{Recommended Citation}

Hao, T. H.; Raman, K. S.; and Watson, Richard T., "GROUP DECISION SUPPORT SYSTEMS: THE CULTURAL FACTOR" (1989). ICIS 1989 Proceedings. 38.

http://aisel.aisnet.org/icis1989/38

This material is brought to you by the International Conference on Information Systems (ICIS) at AIS Electronic Library (AISeL). It has been accepted for inclusion in ICIS 1989 Proceedings by an authorized administrator of AIS Electronic Library (AISeL). For more information, please contact elibrary@aisnet.org. 


\title{
GROUP DECISION SUPPORT SYSTEMS: THE CULTURAL FACTOR
}

\author{
T. H. Ho \\ K. S. Raman \\ Department of Information Systems and Computer Science \\ National University of Singapore \\ Richard T. Watson \\ Department of Management \\ University of Georgia
}

\begin{abstract}
Information technologies are socio-technical in that they consist of people (the human or "socio" side), non-human resources (the technical side), and the interaction between these two. They cannot be culture-free because the cultural factor associated with the human component will always be present. An information technology that is appropriate in one national culture is not necessarily appropriate in another. This paper reports an empirical study of group decision support systems (GDSS) conducted in Singapore. It describes the cultural differences between the USA and Singapore and discusses how these differences may affect the application of the existing body of GDSS findings to Singapore. This cross-cultural analysis of GDSS research findings is based on two studies carried out in the USA and Singapore. By adopting a very similar research design and employing the same GDSS software and research task, the authors are able to eliminate most of the contextual variables and the situational factors that might possibly account for the differences in research findings and explain these differences in terms of cultural factors. The key findings of the cross-cultural analysis are:
\end{abstract}

1. The anonymity feature of a GDSS allowed dominant members in Singaporean GDSS groups to openly express negative opinions about other group members' contributions, a behavior that would otherwise be culturally unacceptable. This, in turn, led to dissatisfaction and lower post-meeting consensus among group members. This phenomenon was not obvious in the American GDSS groups.

2. While structure facilitated expression of agreement or conflict in the American groups, it did not help Singaporean groups. Structure forced group members to be direct and open, a feature that is undesirable in Singaporean culture in which members prefer to express disagreement in an indirect manner so as to preserve harmony.

3. Use of a GDSS led to more even member influence in American groups but resulted in less even member influence in Singaporean groups. The anonymity feature of a GDSS allowed more equal member participation in both cultures. However, it also allowed a dominant member in a Singaporean group to gain influence without direct confrontation with other group members. This resulted in lower equality of influence in the Singaporean GDSS groups.

\section{INTRODUCTION}

Research suggests that there are cross-cultural differences among nationals and these differences have important implications for group researchers and organization scientists. Scientific theories in psychology, sociology, and organizational behavior that deal with humans and organizations are culturally specific: a theory that applies in one culture does not necessarily apply in another culture (Hofstede 1980, 1984, 1985). As GDSS technology has a direct impact on the communication patterns of groups, a theory of GDSS may need to incorporate the cultural factors. A review of GDSS research (Kraemer and
Pinsonneault 1989; Dennis et al. 1989) indicates that all existing empirical GDSS research has been conducted in the USA using American subjects. The applicability of this body of GDSS research findings in an oriental culture, for example the Singaporean culture, is unknown. A crosscultural study of GDSS will help determine the applicability of these research findings in an oriental cultural environment and fill a significant gap in the GDSS research (Nunamaker and George 1987).

An important criterion underpinning GDSS design practice is the assumption that the addition of the anonymous electronic medium to verbal information exchange in a 
group will lead to more balanced involvement of group members and better decision outcomes. It is frequently argued that a GDSS enables group members to express their opinions anonymously, and hence allows those group members who may be reticent about verbally communicating their views to use the computer as a medium for influencing the process and outcome of the meeting. Consequently, the decision-making processes become more democratic and the resources of a group are better extracted in a group discussion (DeSanctis and Gallupe 1987). This theory of GDSS makes three implicit assumptions which may be culturally specific. First, the theory assumes that it is important for each group member to have an equal opportunity, regardless of status differentials, to express an opinion in a group discussion and satisfaction of each group member comes from an equal opportunity to influence the group or present information to the group. Second, the theory assumes that each group member prefers open and direct communication to indirect communication to resolve conflict or disagreement in a group discussion. This assumption is reflected in existing GDSS designs which impose a meeting structure that encourages group members to state their views clearly and have more open communication. Third, the theory assumes that group decision should maximize organizational objectives rather than group harmony. This is reflected in existing GDSS designs, where task-oriented considerations have precedence over social-oriented considerations. While these assumptions may be valid in the American culture, they may not be valid in Singaporean culture. In Singaporean culture, "belongingness" may come above ego-needs like self-actualization and self-esteem. In addition, disagreement is usually more effectively expressed in indirect ways than in direct and open confrontation. Moreover, preserving group harmony may be more important than maximizing organizational objectives in a group discussion (Hofstede 1980).

This study aims to examine the impacts of GDSS in Singaporean culture and to compare the research findings of the study with those of a very similar study carried out in the USA. This cross-cultural analysis attempts to assess the importance of cultural differences in the study of the impacts of GDSS on decision outcomes. Both studies adopted very similar research design, solved a preference allocation task that required resolution of competing personal preference structures, and used the same Software Aided Meeting Management (SAMM) system that was developed at the University of Minnesota.

The organization of this paper is as follows: Section 2 articulates the conceptual foundations of the research. It presents a conceptual framework for the study of groups and derives a causal model from this framework for the study. It also describes four important cultural dimensions that differentiate one national culture from another, and discusses their implications for decision making. Section 3 reviews relevant prior research on GDSS, paying particular attention to empirical GDSS research. Section 4 identifies the relevant dependent variables and presents the research hypotheses. Section 5 describes the research methodology. Section 6 presents the statistical analysis of the data and the research results. Section 7 provides a cross-cultural analysis of the research findings and examines the implications of the cultural factor in GDSS research.

\section{THE CONCEPTUAL FOUNDATIONS OF THE RESEARCH}

The conceptual foundations for this research are the theory of small group dynamics and observed differences in workrelated values between cultures. McGrath's (1984) framework for the study of groups is used to derive a causal model. The four cultural factors identified by Hofstede (1980) provide a basis for understanding cultural differences that could impact the use of a GDSS.

\subsection{The Causal Model}

McGrath's framework has been suggested as a suitable theoretical basis for investigating the effects of GDSS (Poole, Siebold and McPhee 1985; Zigurs, Poole and DeSanctis 1987; Watson 1987). According to this framework, the central feature of a group lies in the interaction of its members -- the behavior together of two or more persons. There are four major classes of properties that set the conditions under which group interaction takes place:

- The biological, social, and psychological properties of individuals

- The physical, socio-cultural, and technological properties of environment(s)

- The patterned relations among group members prior to meeting (the standing group)

\section{- The characteristics of group task}

The effects of these four sets of properties, singly and in combination, are the forces that shape the group interaction process. The group interaction process itself is both the result of these shaping forces and the source of some additional forces. The interaction process and its results represent forces that potentially lead to changes in the input variables. For example, the level of consensus of a group (a property of a standing group) prior to a meeting will influence the group interaction process, and the interaction process will, in turn, lead to changes in the level of consensus after the meeting. In other words, the input classes of variables and the group interaction process interact with each other.

The causal model, which is derived from this framework, is given in Figure 1. This model asserts that the behavior 
of the acting group is influenced by the type of decision support and the pre-meeting consensus of the standing group.

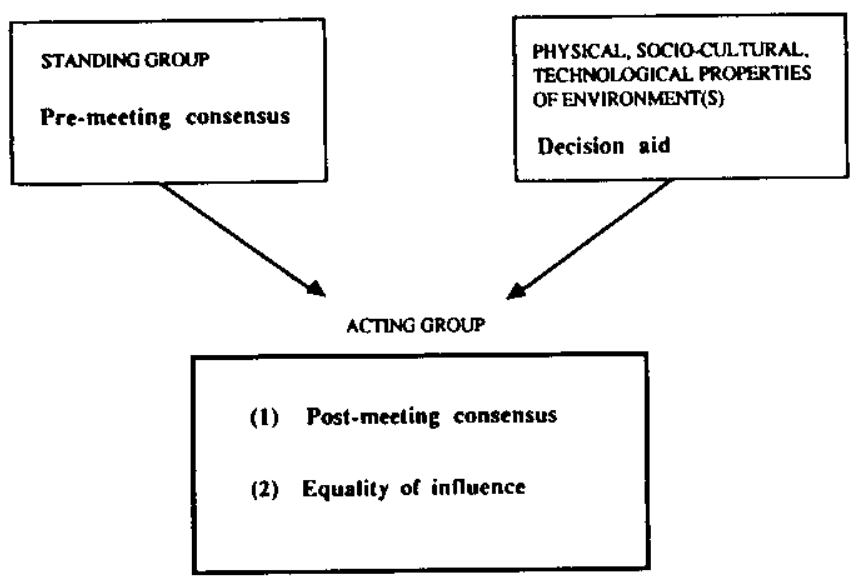

Figure 1. A Causal Model

The group task is a preference allocation task that requires resolution of competing preference structures. A preference allocation task occurs when a group agrees upon its goals and purposes, but disagrees on how to achieve its common objective. It is a convergent task that requires achieving of group consensus. It has no correct solution.

Two properties of the acting group are of interest: the level of post-meeting consensus and the equality of influence. The level of consensus of a group that solves a conflict resolution task is a key measure of the degree of success in a group discussion because it is related to the level of commitment of each member to the group's decision after the meeting and it affects the group's stability in the long term. Equality of influence, which is related to degree of member domination, is an important measure because it tells us the influence patterns of group members and reveals how group members arrive at the group's decision.

\subsection{Cultural Factor in Decision Making}

According to McGrath's framework, cultural factors are properties of individuals that also influence the group interaction process. If we wish to conduct cross-cultural analysis of group behaviors, it is necessary to take cultural factors into consideration and examine the effects of cultural differences on the group interaction process. Cultural differences between nationals have been extensively researched by Hofstede $(1980,1984,1985)$. In a major piece of cross-national research, Hofstede (1980) has identified four dimensions of national culture on the basis of statistical analysis of 116,000 questionnaires completed by members of one large US-based multinational corporation with operating units in $\mathbf{4 0}$ countries around the world.
Hofstede matched employees in terms of jobs, age, and sex and argued that he had isolated national culture as an independent variable. The four major dimensions (dependent variables) identified by Hofstede are individualism (IDV), power distance (PDI), uncertainty avoidance (UAI), and masculinity (MAS). The four dimensions are defined below.

- Individualism (IDV) stands for a preference for a loosely knit social framework in society in which individuals are supposed to take care of themselves and their immediate families only, as opposed to collectivism, which stands for a preference for a tightly knit social framework in which individuals can expect their relatives, clan, and other in-group to look after them in exchange for unquestioning loyalty.

- Power distance (PDI) is the extent to which society accepts the fact that power in institutions and organizations is distributed unequally.

- Uncertainty avoidance (UAI) is the degree to which a society feels threatened by uncertain and ambiguous situations, which leads them to support beliefs promising certainty and to maintain institutions protecting conformity.

- Masculinity (MAS) stands for a preference for achievement, heroism, assertiveness, and material success, as opposed to Femininity, which stands for a preference for relationships, modesty, caring for the weak, and the quality of life.

\subsubsection{Western-English Language Culture}

The scores of these four cultural dimensions for the USA, Australia, Canada and Ireland are summarized in Table 1. These countries are identified by Hofstede as having a similar culture and may be conveniently labelled as Western-English language culture. This culture is characterized by high IDV and relatively lower PDI scores. A person in this culture will tend to see him/herself as "I" and strive for self-actualization. Status differentials are usually considered undesirable. In addition, status tends to be based on the personal merit of the individual or what one has done.

\subsubsection{Eastern-English Language Culture}

The scores on the four dimensions for four other culturally similar nations (Singapore, Hong Kong, Indonesia, and the Philippines) are summarized in Table 2. These countries can be classified as Eastern-English language culture. This culture is characterized by lower IDV and relatively higher PDI scores. A person in this culture will tend to see him/herself as part of "we" and strive for group interest. Both superiors and subordinates expect power differences 
to be translated into visible status differentials. In addition, status is often based on rank and ancestry or who one is supposed to be.

Table 1. Western-English Cultures with Scores

\begin{tabular}{|l|l|l|l|l|}
\hline Country & IDV & PDI & UAI & MAS \\
\hline USA & 91 & 40 & 46 & 62 \\
\hline Australia & 90 & 36 & 51 & 61 \\
\hline Canada & 80 & 39 & 48 & 52 \\
\hline Ireland & 70 & 28 & 35 & 68 \\
\hline
\end{tabular}

Table 2. Eastern-English Cultures with Scores

\begin{tabular}{|l|c|l|l|l|}
\hline Country & IDV & PDI & UAI & MAS \\
\hline Singapore & 20 & 74 & 8 & 48 \\
\hline Hong Kong & 25 & 68 & 29 & 57 \\
\hline Indonesia & 14 & 78 & 48 & 46 \\
\hline Philippines & 32 & 94 & 44 & 64 \\
\hline
\end{tabular}

\subsubsection{Cross-cultural Differences}

Research findings in one nation may be generalizable to another nation of the same culture but not across cultures. Instances have been cited (Hofstede 1980, 1984, 1985) to show the various problems of generalizing a management philosophy of one culture to another. Tables 1 and 2 demonstrate that the USA and Singapore belong to a different cultural group. The American culture is characterized by high individualism and relatively lower power distance. Singaporean culture is characterized by low individualism and relatively higher power distance. The significance of these cultural differences for GDSS research needs further discussion.

In the individualistic American culture, self-actualization is the supreme need and a typical choice for an individual as suggested in Maslow's (1954) theory of need hierarchy. In the more collectivist Singaporean culture, "belongingness" may come above ego-needs such as self actualization and esteem, and people will have a supreme need for actualizing their in-group which may in fact require giving all for maintaining harmony with others. In individualist cultures, openness and directness in work relations are often considered virtues. Conflict resolution in the open may be preferred to consensus building behind closed doors (Hofstede 1980). In collectivist cultures with a tightly knit social framework, there is generally an extensive set of expectations about interpersonal behaviors. Violating these expectations would threaten the social framework. Therefore maintenance of the proper forms and harmony is usually considered preferable to openness which could lead to disharmony. In addition, the leader in such a culture is normally expected to build consensus for maintaining harmony in the society (Raman and Rao 1988; Raman, Ho and Watson 1988; The Straits Times 1988).

This difference in individualism is important in understanding the impacts of a GDSS when it is applied to the two countries. In Singaporean culture, group members may prefer indirect ways over open and direct communication to resolve conflict and disagreement. Therefore, the structure feature of a GDSS which encourages open communication may not be appropriate for Singaporean groups. The anonymity feature of a GDSS may have both positive and negative consequences when it is applied to Singaporean groups. On the one hand, it may encourage more even member participation. On the other hand, dominant members may use the anonymity feature to openly express negative opinions about other members' contributions, a behavior that would otherwise be unacceptable in the culture. Dominant members can also take advantage of the anonymity feature to gain influence without direct confrontation. Moreover, preserving group harmony may be more important than maximizing organizational objectives, and social-oriented considerations may come above task-oriented considerations in the Singaporean culture. As a GDSS tends to reduce socialoriented communication among group members, it may bring some unintended consequences into the group interaction process.

In a large power distance society such as Singapore, respect for hierarchy means that a subordinate would submit to a superior's direct or indirect message. Joint goal setting by both superior and subordinate, and joint appraisal against these goals after an operation period, are considered inappropriate. In a small power distance society such as the USA, these activities are relatively common (e.g., Management by Objectives). This difference in power distance has important implications in the implementation of GDSS technology in the two countries. In Singapore, management may be less willing to introduce GDSS technology because it may threaten existing power relations and structures, and subordinates may be unwilling to participate freely out of fear of reprisals. This unwillingness may extend to the condition of anonymity.

\section{EXPERIMENTAL GDSS LITERATURE REVIEW}

This section analyzes the existing body of empirical findings on the impacts of GDSS on groups. The review will focus on those empirical studies that are most relevant to this study. A more complete review of the literature can be found in Kraemer and Pinsonneault (1989) and Dennis 
et al. (1989). Kraemer and Pinsonneault develop a framework from the literature of organization behavior and group psychology for organizing and analyzing the literature on GDSS. They differentiate two broad technological support systems for group processes: Group Decision Support Systems (GDSS) and Group Communication Support Systems (GCSS). In their classification, the support system used in this experiment would be called GCSS. In this study, however, we do not differentiate the two because we believe that group decision processes cannot be separated from group communication processes and the distinction is really a matter of degree of intervention into group interaction processes (DeSanctis and Gallupe 1987).

Nearly all empirical research in GDSS (the Zigurs, Poole and DeSanctis [1987] process study is an example of an exception) has adopted input-output perspective and compared the decision outcomes of GDSS groups with traditional, face-to-face groups. Common dependent variables used are decision quality, consensus, equality of participation, domination by a few members, and satisfaction with the process. Two pieces of research have included an additional treatment where groups were manually supported by structure that was equivalent to the GDSS support (Lewis 1987; Watson 1987). In these two research studies, the manually supported groups were used to isolate the impact of structure on group decision making so that the impact of GDSS technology, over and above the impact of structure, could be determined.

The findings from the existing body of research have not been very consistent. This is partly because different studies use different GDSS systems, solve different tasks, and employ different research strategies in the conduct of their research. However, in general, the use of a GDSS appears to lead to better quality decisions. Three studies (Steeb and Johnston 1981; Turoff and Hiltz 1982; Gallupe 1985) reported that GDSS groups made better quality decisions than baseline groups (baseline groups were freely-interacting and received no support whatsoever). Two studies (Lewis 1987; Watson 1987) reported no significant difference between GDSS and baseline groups. Lewis also reported that GDSS groups made better decisions than manually supported groups (manually supported groups were provided with flip-chart support and meeting agenda similar to the GDSS support). As most of these studies used groups of three to five members, the generality of this finding to larger groups may be limited. In addition, most of these groups were in their early stages of development, when members do not focus on task (Kraemer and Pinsonneault 1989). This means that a GDSS may not lead to better quality decisions for groups who are in their advanced stages of development and are already task-oriented (Kraemer and Pinsonneault 1989). The use of GDSS also tends to lead to more even participation from the group members and reduce domination by a few group members. Siegel et al. (1986), Lewis (1987) and Nunamaker, Applegate and Konsynski (1987, 1988) reported more equal participation from GDSS groups. Two other studies (Watson 1987; Gallupe 1985), however, reported no significant difference between GDSS groups and baseline groups. Nunamaker, Applegate and Konsynski (1987, 1988), Lewis (1987), Turoff and Hiltz (1982), and Siegel et al. (1986) found that a GDSS reduced domination by a few group members. The findings seems to suggest that the anonymity feature of a GDSS encourages participation from group members and reduces domination by a few group members. These changes in communication patterns and structures of dominance may only occur at the beginning of group formation. It is not clear whether a GDSS will produce such changes in groups where there are already established patterns of communication and structures of dominance.

On the other hand, the use of a GDSS appears to reduce group consensus. Three studies (Rice 1984; Gallupe 1985; Siegel et al. 1986) indicated that the use of GDSS leads to a lower degree of consensus. Only Turoff and Hiltz (1982) reported that GDSS could help groups to reach consensus. These research findings appear inconsistent with regard to the impact of a GDSS on equality of participation and domination. As a result of more open and even participation, we would expect group members to feel a greater personal commitment towards the group's decision. Kraemer and Pinsonneault (1989) suggest that when a GDSS is applied to groups who are in the early stages of development and the efforts of members are oriented toward establishing position and power over the decision process, a GDSS decreases consensus. If this is so, a GDSS may not affect the consensus of groups who have established their power relations and structures. In addition, GDSS groups appear to be less satisfied with the decision making processes. Only three studies (Steeb and Johnston 1981; Nunamaker, Applegate and Konsynski 1987, 1988) indicated that the GDSS groups were more satisfied with the decision making processes. Of the three studies, the two by Nunamaker, Applegate and Konsynski $(1987,1988)$ used real life managers and involved them in planning tasks. The subjects did not have to resolve conflict to reach consensus, which might explain why they were more satisfied than groups who used GDSS for conflict resolution. On the whole, these research findings seem to be consistent with the findings of lower consensus. Therefore, they could also be related to the stages of group development.

These research findings are tabulated in Table 3 and are presented in an A-B comparison form (e.g., GDSS-Baseline), which means that the mean response of $A$ is compared with the mean response of $B$ for a significant difference. An " $H$ " in a comparison A-B indicates that the mean response of $A$ was found to be significantly higher than the mean response of $B$. An " $L$ " indicates the reverse.

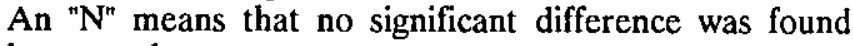
between the mean responses. 
Table 3. GDSS, Manual, and Baseline Support Related to Decision Quality (DQ), Level of Consensus (LC), Equality of Participation (EP), Domination by Members (DM), and Satisfaction with Process (SP)

\begin{tabular}{|c|c|c|c|c|c|c|c|c|c|c|c|c|c|c|c|}
\hline \multirow{2}{*}{ Author } & \multicolumn{5}{|c|}{ GDSS-Baseline } & \multicolumn{5}{|c|}{ GDSS-Manual } & \multicolumn{5}{|c|}{ Manual-Baseline } \\
\hline & $D$ & LC & $E$ & om & s' & $\infty$ & Lc & EP & DM & $\mathbf{s}$ & $\mathbf{D Q}$ & uc & EP & DM & $\mathbf{P}$ \\
\hline $\begin{array}{l}\text { Stoceb and } \\
\text { Johnston, } 1981\end{array}$ & $\mathrm{H}$ & & & & H & & & & & & & & & & \\
\hline $\begin{array}{l}\text { Tumof and } \\
\text { Hilkz, } 1982\end{array}$ & $\mathrm{H}$ & $\mathrm{H}$ & & $L$ & & & & & & & & & & & \\
\hline Rice, 1984 & & L & & & & & & & & & & & & & \\
\hline Gallupc, 1985 & $\mathrm{H}$ & L & $\mathrm{N}$ & & L & & & & & & & & & & \\
\hline $\begin{array}{l}\text { Siegel, el al. } \\
1986\end{array}$ & & L & $H$ & $\mathbf{L}$ & & & & & & & & 、 & & & \\
\hline Lewis, 1987 & $N$ & & $\mathrm{H}$ & $\mathrm{L}$ & $N$ & $\mathrm{H}$ & & H & $L$ & N & $\mathrm{N}$ & & $\mathrm{N}$ & $\mathbf{N}$ & $\mathbf{N}$ \\
\hline Walson, 1987 & N & $N$ & $N$ & $N$ & L & 2 & $\mathrm{~N}$ & N & $\mathrm{N}$ & $L$ & $\mathbf{N}$ & $\mathrm{N}$ & $\mathbf{N}$ & $N$ & L \\
\hline $\begin{array}{l}\text { Numamaker, at al. } \\
\text { 1987. 1988 }\end{array}$ & & & $H$ & $\mathbf{L}$ & $\mathrm{H}$ & & & & & & & & & & \\
\hline
\end{tabular}

\section{VARIABLES AND HYPOTHESES}

The independent variable for this study was the level of support (decision aid). Three levels of support were used. GDSS groups received a Level-1 GDSS support. Level-1 GDSSs provide technical features aimed at removing common communication barriers, such as a large screen for instantaneous display of ideas, voting solicitation and compilation, anonymous input of idcas and preferences, and electronic message exchange between members (DeSanctis and Gallupe 1987). Manual groups were provided with flip-chart support with a meeting agenda similar to the GDSS supported groups. As discussed before, this was to isolate the effects of the structure from the effects of the communication channel. Baseline groups were freely-interacting and received no support whatsoever. Dependent variables included post-meeting consensus and equality of influence. Using these variables, two major hypotheses were developed. These hypotheses were derived from the theory of GDSS proposed by DeSanctis and Gallupe and hence were written for a Western-English Language culture. This theory argues that a GDSS improves information exchange by facilitating the interac- tive sharing and use of information among group members. This improvement in information exchange leads to a more democratic decision making process with more even member participation. These hypotheses have not been changed for a Eastern-English language culture so as to provide a basis for discerning cultural differences between the two cultures.

Prior to the meeting, the members of a group each have a set of preferences with regard to the issue at hand. Following a discussion, group members may alter their preferences to align more closely with the group's decision. The type of decision support provided to a group can influence this shift in an individual's preferences because it changes the communication patterns of the group. As discussed above, GDSS leads to a more even member participation. Consequently, GDSS group members should have a higher commitment to the group decisions, and hence display a higher degree of post-meeting consensus. Using a similar argument, we can also conclude that manual groups who are provided with a structured approach to group decision making, compared to the freely interacting groups, should attain a higher level of postmeeting consensus.

H1: Level of post-meeting consensus is a function of the type of support given to the group.

H1a: Level of post-meeting consensus will be higher in the GDSS groups than in the manual groups or the baseline groups, controlling for the premeeting consensus.

H1b: Level of post-meeting consensus will be higher in the manual groups than in the baseline groups, controlling for the pre-meeting consensus.

Equality of influence measures how equal the members' influence is in a group discussion. It is usually considered desirable to have higher equality of influence in a group discussion where no group member's opinion is considered more worthy than another. The presence of an anonymous communication channel and the imposition of a structure encourage those group members who are unwilling to communicate to participate and potentially influence the group discussion. As a result, groups who are supported by GDSS should display a higher equality of influence than manual groups or baseline groups. Using a similar argument, manual groups who are provided with a structured approach to group decision-making should display a higher equality of influence than baseline groups.

H2: Equality of influence is a function of the level of support given to the group.

H2a: Equality of influence will be higher in the GDSS groups than in the manual and the baseline groups, controlling for pre-meeting consensus. 
H2b: Equality of influence will be higher in the manual groups than in the baseline groups, controlling for pre-meeting consensus.

\section{RESEARCH METHOD}

In this section, the background of the subjects, the experimental procedure followed in conducting the experiment, the research task, and the GDSS software used are described.

\subsection{Subjects}

There were 240 undergraduate students who served as subjects for the Singapore experiment. They were formed into 48 five-person groups. All participants had used a computer before. On average, the subjects were 20 years of age. Approximately 65 percent of the subjects were males who had served two and a half years of national service and had worked in teams before. Most subjects knew each other beforehand. Hence, the groups formed were not unlike "task force" groups found in most organizations. The subjects were given course credit for their participation.

\subsection{The Experimental Procedure}

The procedure followed in the conduct of this experiment was the same as that used by Watson (1987). Each experimental session had three phases. In the first phase, each group member allocated funds in five different scenarios. In the second phase, computer-supported groups received training on how to use the GDSS software. During the training session, computer-supported groups followed the agenda provided by the software and entered their inputs at each phase of the agenda. The training session lasted for 45 minutes. Manual groups were provided with an eleven page handout outlining the same agenda that was used on the GDSS (see Figure 2). Baseline groups received no training whatsoever. The third phase was the meeting session in which the groups solved a fund allocation task in each of the controlled experimental conditions described above. The meeting sessions were video-recorded. Following the meeting sessions, two questionnaires were administered. These questionnaires were used to measure other dependent variables. Details of the questionnaires and other dependent variables are reported in Ho (1989).

\subsection{The Task}

The task involved an allocation of funds to six projects based on personal preference structures. This task, which was developed by Watson, requires group members to resolve their conflict to arrive at a solution. This task is more suitable than a real life organizational task because it does not require any explicit knowledge of an area. A real life organizational task would be inappropriate for the student subjects because they have limited organizational experience.

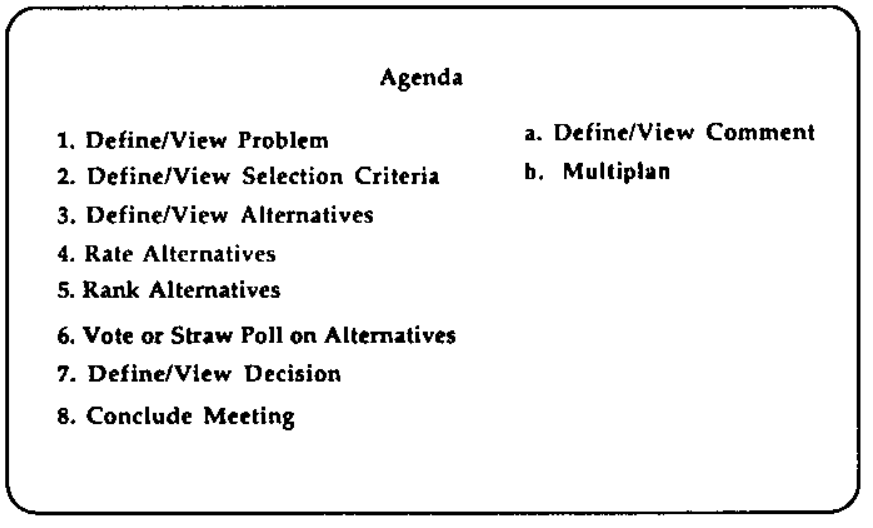

Figure 2. The Main Menu of SAMM

\subsection{The GDSS: Software Aided Meeting Management (SAMM)}

The GDSS used was the SAMM system, which is described in DeSanctis, Sambamurthy and Watson (1987). The main menu of SAMM is illustrated in Figure 2.

The left hand side of the screen shows a standard agenda that a group may follow when conducting a meeting. The right hand side provides decision aids that can be accessed at any stage during the meeting. In this experiment, the decision aids option was not used. The software has seven features: problem definition, input of selection criteria, input of alternatives, rating, ranking, voting, and solution definition. These features aim to reduce process losses in group meetings and to support primarily the communication needs of groups.

In this experiment, the GDSS system was established in a decision room (DeSanctis and Gallupe 1987). The system provided each group member with a terminal and had a public screen to facilitate group communication. Each group member, through his private terminal, could enter and send individual inputs to the public screen which could be viewed by all other members.

\section{RESULTS}

Analysis of covariance (ANCOVA) was used to test for a significant overall effect for the independent variable. The covariate was the level of consensus prior to the meeting. If a significant effect was found for the independent variable, a REGW multiple $F$ test was performed on all main effects means. 


\subsection{Post-Meeting Consensus}

Post-meeting consensus was measured by a method developed by Spillman, Spillman and Bexdek (1980) and later adapted by Watson (1987). The measure gives a post-meeting consensus score ranging from zero to one, where one means complete agreement in the group. Table 4 summarizes the measurement of post-meeting consensus for each treatment.

Table 4. Post-meeting Consensus

Mean score (standard deviation and cell size) Decision aid

\begin{tabular}{|l|l|l|l|}
\hline Baseline & Manual & GDSS & Totals \\
\hline 0.556 & 0.636 & 0.483 & 0.558 \\
$(0.18,14)$ & $(0.21,16)$ & $(0.12,15)$ & $(0.18,45)$ \\
\hline
\end{tabular}

The overall ANCOVA revealed a significant main effect for decision aid $(F=4.05, p=0.027)$. The REGW test indicated that manually supported groups displayed a higher level of post-meeting consensus than the GDSS groups. This is opposite to what was hypothesized. Hence, there is no support for Hypothesis H1a and H1b. There was a significant interaction effect between decision aid and covariate $(F=3.42, p=0.045)$. To further explore the interaction effect of decision aid and pre-meeting consensus (covariate), the correlation between postmeeting consensus and pre-meeting consensus was examined. Table 5 shows that there is a significant correlation between post-meeting consensus and pre-meeting consensus in baseline groups, but there is no significant correlation in the manually supported and GDSS supported groups. Figure 3 suggests that, in baseline groups, postmeeting consensus is positively related to the pre-meeting consensus.

Table 5. Correlation between Pre-meeting Consensus and Post-meeting Consensus by Decision Aid

Decision Aid

\begin{tabular}{|l|l|l|l|}
\hline & Baseline & Manual & GDSS \\
\hline Correlation cocfficient & 0.583 & -0.393 & 0.463 \\
Significance & 0.0287 & 0.1319 & 0.082 \\
\hline
\end{tabular}

\subsection{Equality of Influence}

Equality of influence was measured using the method developed by Watson. In this method, each group member's choice and the group's decision are represented by points in a decision space. The method calculates the "geometrical distance" of each individual's choice from the point of equal influence and from the group's decision. The point of equal influence is the mid point of the group members' choices. The ratio of the two distances for each group member gives his relative influence upon the group's decision. Equality of influence is then calculated using these individual influence scores. The measure produces a positive number where a score of zero means even influence in the group; the higher the score, the less even the influence. Table 6 summarizes the measurement of equality of influence for each treatment.

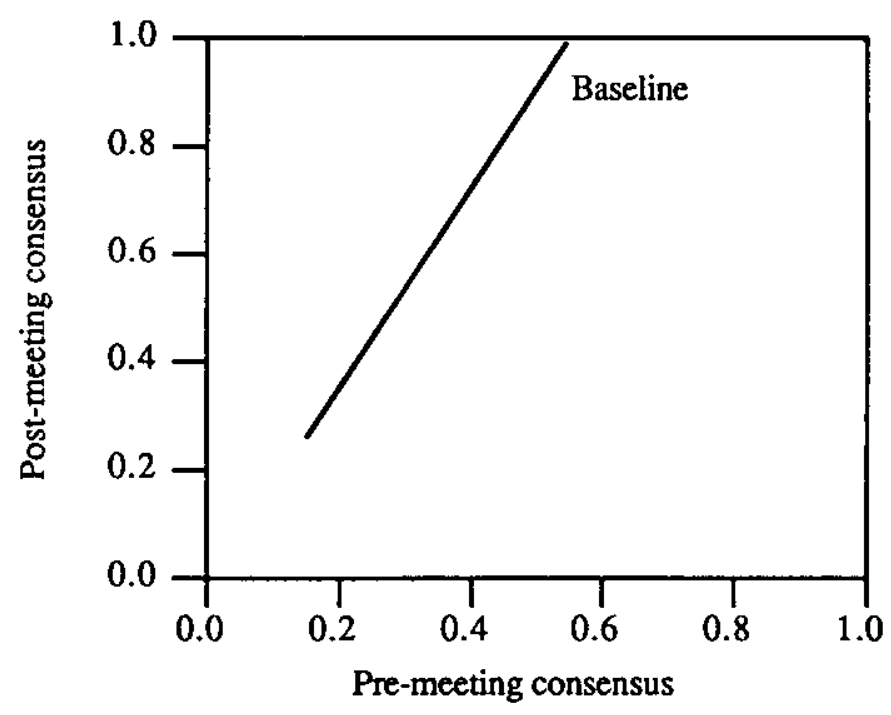

Figure 3. Post-meeting Consensus as a Function of Pre-meeting Consensus in the Baseline Condition

Table 6. Equality of Influence Mean Score (standard deviation and cell size) Decision Aid

Decision Aid

\begin{tabular}{|l|l|l|l|}
\hline Baseline & Manual & GDSS & Totals \\
\hline 0.49 & 0.62 & 1.03 & 0.72 \\
$(0.26,14)$ & $(0.69,16)$ & $(0.91,15)$ & $(0.70,45)$ \\
\hline
\end{tabular}

The ANCOVA model revealed no significant effect for the independent variable. Hence, there is no support for Hypothesis $\mathrm{H} 2 \mathrm{a}$ and $\mathrm{H} 2 \mathrm{~b}$. The power value for this test is 0.28 . This suggests that the sample size may have been too small to detect the effect of decision aid on equality of influence. A higher mean score in the GDSS condition would suggest that GDSS groups exhibit a potential to be less even in their influence. This appears to be inconsistent with the findings of the existing GDSS literature. Higher variance in the GDSS condition would suggest that GDSS technology increases the dispersion across groups with respect to member influence. 


\section{CROSS-CULTURAL ANALYSIS}

The results from this study are different from a very similar study conducted in the USA (Watson 1987). As both studies have a very similar research design, it would be worthwhile to examine the underlying factors that account for the different research findings. Both studies used the same measuring instruments and GDSS software, and solved the same research task with student subjects. However, there were two differences between the two research designs. First, this study used groups of five members whereas Watson's study used group of three or four members. Second, the subjects in the two studies were of two very different cultural origins. These differences merit some elaboration.

Watson found no significant differences in main responses of post-meeting consensus and equality of influence between groups of three and four members. Therefore, it is likely that this pattern of results may extend to groups of five as well. In fact, examining the data from a few groups of four members in this study (data from groups with an absence of a group member) appears to confirm this generalization. Initial examination of the communications patterns of Singaporean groups from the video-tapes of the meeting sessions suggests that Singaporean groups were indirect in their communication and seldom expressed disagreement in an open manner. Cross-cultural literature (Hofstede 1980, 1984, 1985) suggests a strong cultural difference between the two countries. Therefore, the cultural factor appears to be the most probable explanation for the different research findings. Table 7 illustrates the differences between research findings of the two research studies.

Table 7. The Differences between the Research Findings

\begin{tabular}{|c|c|c|}
\hline $\begin{array}{l}\text { Dependent } \\
\text { Variables }\end{array}$ & $\begin{array}{l}\text { American } \\
\text { Groups }\end{array}$ & $\begin{array}{l}\text { Singaporean } \\
\text { Groups }\end{array}$ \\
\hline $\begin{array}{l}\text { Post-meeting } \\
\text { Consensus }\end{array}$ & $\begin{array}{l}\text { No significant difference } \\
\text { between the experimental } \\
\text { groups }\end{array}$ & $\begin{array}{l}\text { Manual groups display a } \\
\text { higher level of post-meeting } \\
\text { consensus than GDSS } \\
\text { groups } \\
\text { Post-meeting consensus is } \\
\text { significantly correlated with } \\
\text { pre-meeting consensus in } \\
\text { baseline groups }\end{array}$ \\
\hline $\begin{array}{l}\text { Equality of } \\
\text { Influence }\end{array}$ & $\begin{array}{l}\text { The mean score of GDSS } \\
\text { is the lowest } \\
\text { (more even) }\end{array}$ & $\begin{array}{l}\text { The mean socre of GDSS } \\
\text { groups is the highest } \\
\text { (less even) }\end{array}$ \\
\hline
\end{tabular}

In the American culture, openness and directness in discussion is often considered a virtue. In Singaporean culture, the reverse is true. Disagreement is usually more effectively expressed in indirect ways than in direct con- frontation. Negative opinions about other members' views are seldom expressed openly. The anonymity feature of a GDSS allowed dominant members in Singaporean GDSS groups to openly express negative opinions about other group members' contribution, a behavior that would otherwise be culturally unacceptable. This domination led to dissatisfaction among group members and lowered members' commitment towards group decision. Hence, it lowered group consensus after the meeting. The same phenomenon was not observed in American GDSS groups. This is a possible explanation of the significantly lower post-meeting consensus of Singaporean GDSS groups.

While imposing structure facilitated expression of disagreement or conflict in the American groups, it did not help in Singaporean groups. Structure forced group members to be direct and open, an undesirable feature in Singaporean culture in which members preferred to express disagreement in an indirect manner so as to preserve harmony. Group members in Singaporean groups found it difficult to express their preferences directly if their preferences were different from those of other group members. Consequently, Singaporean groups in the baseline condition found it most "natural" and easiest to express their preferences. On the other hand, the American groups found it "natural" to express disagreement in an open manner and were not threatened by the imposition of structure. There is also a subtle difference between the effects of imposing a structure in GDSS and manual groups in Singaporean culture. The availability of multiple electronic communication channels in GDSS groups allows group members to enter their inputs in parallel at each phase of the meeting agenda. Each group member is not aware of other members' preferences when he enters his inputs. On the other hand, group members in manual groups have to "enter" their inputs serially since they cannot all speak at the same time. Group members who express their opinions later tend to "hide" their preferences. This may explain why the correlation between post-meeting consensus and pre-meeting consensus is different in GDSS and in manual groups.

The anonymity feature led to more even participation in both the American and Singaporean GDSS groups, but it had a negative consequence in Singaporean culture. Group members in Singaporean groups were face-conscious and avoided direct confrontation with other group members. The anonymity feature of GDSS allowed a dominant member in a Singaporean GDSS group to take advantage of the feature to gain influence without direct confrontation with other group members. This was manifested by the fact that a dominant member in a Singaporean GDSS group tended to openly express negative opinions about other group members' contributions and positive opinions about his or her own inputs to gain influence. Therefore, equality of influence was lower in Singaporean GDSS groups.

This cross-cultural analysis also suggests that GDSS cannot help decision-making groups in reaching consensus for a 
conflict resolution task. This is true in both cultures. Rao and Jarvenpaa (1989) suggest that the anonymity feature of GDSS reduces commitment of group members towards their inputs. This lowering of commitment is an important factor in groups solving convergent tasks because in such situations it is necessary for group members to actively defend their ideas for consensus formation. This crosscultural analysis provides support for this conceptual model which is based on commitment theory.

It is clear from the cross-cultural analysis that cultural factors have important implications in the application of existing GDSS findings to Singapore. The challenge for GDSS research is to incorporate these cultural factors into existing GDSS designs, identify those situations where GDSS will be most helpful, and examine as well as account for those factors that might possibly hinder the implementation of GDSS in Singapore.

The findings from this cross-cultural analysis must be applied to different settings with care. The results are software (SAMM) and task specific and seemed to be heavily influenced by the anonymity feature of a GDSS. The results may be different when GDSS is used without anonymity in creativity and planning tasks.

\section{ACKNOWLEDGEMENTS}

Professor Gerardine DeSanctis provided the SAMM software and offered many useful suggestions during the course of this research. AT\&T International, Singapore Office provided an AT\&T 3B2 500 computer for the experiment. The National University of Singapore GDSS research team members Mr. Lim Lai Huat and Dr. Wei Kwok Kee participated in the research design and conduct of the experiments.

\section{REFERENCES}

Dennis, A. R.; George, J. F.; Jessup, L. M.; Nunamaker, J. F., Jr.; and Vogel, D. R. "Information Technology to Support Electronic Meetings." MIS Quarterly, Volume 12, Number 4, 1988, pp. 591-624.

DeSanctis, G., and Gallupe, R. B. "A Foundation for the Study of Group Decision Support Systems." Management Science, Volume 33, Number 5, 1987, pp. 589-609.

DeSanctis, G.; Sambamurthy, V.; and Watson, R. T. "Computer-Supported Meetings: Building a Research Environment." Large Scale Systems, Volume 13, 1987, pp. 43-59.

Gallupe, R. B. The Impact of Task Difficulty on the Use of Group Decision Support Meeting. Unpublished Ph.D. Dissertation, University of Minnesota, 1985.
Ho, T. H. "An Empirical Study of GDSS Use in FivePerson Groups With and Without Elected Leadership." Unpublished M.Sc. Dissertation, National University of Singapore, 1989.

Hofstede, G. Culture's Consequences: International Differences in Work-Related Values, Beverly Hills: Sage Publications, 1980.

Hofstede, G. "Cultural Dimensions in Management and Planning." Asia Pacific Joumal of Management, January 1984, pp. 81-99.

Hofstede, G. "The Interaction Between National and Organizational Value System." Journal of Management Studies, July 1985, pp. 347-357.

Kraemer, K. L., and Pinsonneault, A. "The Implication of Group Support Technologies: An Evaluation of the Empirical Research." Proceedings of the Twenty-Second Hawaii. Intemational Conference on System Sciences, Hawaii, 1989.

Lewis, L. F. "A Decision Support System for Face-to-Face Groups." Joumal of Information Science, Volume 13, 1987, pp. 211-219.

Maslow, A. H. Motivation and Personality, New York: Harper, 1954.

McGrath, J. E. Groups: Interaction and Perfornance, Englewood Cliffs: Prentice-Hall, 1984.

Nunamaker, J. F., Jr.; Applegate, L. M.; and Konsynski, B. R. "Computer-Aided Deliberation: Model Management and Group Decision Support." Joumal of Operations Research, December 1988.

Nunamaker, J. F., Jr.; Applegate, L. M.; and Konsynski, B. R. "Facilitating Group Creativity: Experience With a Group Decision Support System." Joumal of Management Information Systems, Volume 3, Number 4, 1987, pp. 5-19.

Nunamaker, J. F., Jr., and George, J. F. "Group Decision Support Systems in Pacific Rim Nations: Replicating the Arizona GDSS Studies." Unpublished Working Paper, University of Arizona, 1987.

Poole, M. S.; Siebold, D. R.; and McPhee, R. D. "Group Decision-Making as a Structurational Process." Quarterly Joumal of Speech, Volume 71, 1985, pp. 74-102.

Raman, K. S.; Ho, T. H.; and Watson, R. "Group Decision Support Systems (GDSS): Application in Pacific Rim Countries." Paper Presented at the International Seminar and Exhibition, Computerization for Development -- The Research Challenge, August 1988, Kuala Lumpur, Malaysia. 
Raman, K. S., and Rao, K. V. "Group Decision Support Systems for Public Bodies." PRIISM Working Paper 88-013, University of Hawaii, May 1988.

Rao, V. S., and Jarvenpaa, S. L. "Computer Support of Groups: A Search for Theoretical Models." Proceedings of the Twenty-Second Hawaii International Conference on System Sciences, Hawaii, 1989.

Rice, R. E. "Mediated Group Communication." In R. E. Rice (Editor), The New Media: Communication, Research, and Technology, Beverly Hills: Sage, 1984, pp. 130-154.

Siegel, J.; Dubrovsky, V.; Kiesler, S.; and McDurie, T. W. "Group Processes in Computer-Mediated Communication." Organization Behavior and Human Processes, Volume 37, 1986, pp. 157-187.

Spillman, B.; Spillman, R.; and Bexdek, J. "A Fuzzy Analysis of Consensus in Small Groups." In P. P. Wang and S. K. Chang (Editors), Fuzzy Sets: Theory and Application to Policy Analysis and Information Systems, New York: Plenum, 1980, pp. 291-308.
Steeb, R., and Johnston, S. C. "A Computer-Based Interactive System for Group Decision Making." IEEE Transaction on Systems, Man, and Cybernetics, Volume 11, Number 8, 1981, pp. 544-552.

The Straits Times, Singapore. "My Job is to Forge Consensus, Not Encourage Dissent." July 31, 1988.

Turoff, M., and Hiltz, S. R. "Computer Support for Group Versus Individual Decisions." IEEE Transaction on Systems, Man, and Cybernetics, Volume 30, Number 1, 1982, pp. 82-91.

Watson, R. T. Study of Group Decision Support System Use in Three and Four Person Groups for a Preference Allocation Decision. Unpublished Ph.D. Dissertation, University of Minnesota, 1987.

Zigurs, I.; Poole, M. S.; and DeSanctis, G. "A Study of Influence in Computer-Mediated Decision Making." MISRC Working Paper Number 88-07, University of Minnesota, 1987. 